\title{
Specifying the relationship between land use/land cover change and dryness in central Vietnam from 2000 to 2019 using Google Earth Engine
}

\author{
Thy T. M. Pham, ${ }^{\mathrm{a}, *}$ The-Duoc Nguyen $\odot,{ }^{\mathrm{b}}$ Han T. N. Tham, ${ }^{\mathrm{a}}$ \\ Thi N. K. Truong, ${ }^{a}$ Nguyen Lam-Dao, ${ }^{a}$ and Thong Nguyen-Huy $\oplus^{\mathrm{a}, \mathrm{c}}$ \\ ${ }^{a}$ Ho Chi Minh City Space Technology Application Center, Vietnam National Space Center, \\ VAST, Ho Chi Minh, Vietnam \\ ${ }^{b}$ Ho Chi Minh City University of Technology, Laboratory of Earth Resources and Environment, \\ VNUHCM, Ho Chi Minh, Vietnam \\ 'University of Southern Queensland, Centre for Applied Climate Sciences, Toowoomba, \\ Queensland, Australia
}

\begin{abstract}
Land use/land cover (LULC) change and climate change are thought to be closely related and mutually influential, especially in contexts where land is converted for urban expansion or agriculture. We represent a first attempt to specify the relationship between LULC change and dryness in a region of Vietnam that is profoundly affected by climate change. Using the temperature-vegetation dryness index (TVDI), we specified the relationships and changes underway in Vietnam's Ba river basin, one of the largest river systems in the South Central Coast. Using Google Earth Engine, we extracted land use data from Landsat images and calculated TVDI values from Moderate Resolution Imaging Spectroradiometer (MODIS) data for 2000 to 2019 . We found, first, that agricultural area and deforestation rose by $7.2 \%$ and $2.4 \%$ annually, respectively. These changes were driven by economic development, rising crop prices, illegal logging, wildfires, and emergence of new agricultural areas. Second, areas classified in the driest TVDI intervals (dry and very dry) occupied 57\% of the basin in 2019, 70\% of which was agricultural lands and $20 \%$ other (mainly urban and bare lands). These driest land categories expanded at an average rate of $0.08 \%$ to $0.1 \%$ per year. Moreover, $90 \%$ of areas classified as "very wet" and "wet" were forest. We observed a strong relationship between LULC change and TVDI. Climate change and LULC change thus appear to be propelling the basin's climate toward increasing dryness, suggesting the need for policies to reduce the agricultural area and expand forests while developing more adaptive and sustainable livelihoods. (c) The Authors. Published by SPIE under a Creative Commons Attribution 4.0 Unported License. Distribution or reproduction of this work in whole or in part requires full attribution of the original publication, including its DOI. [DOI: 10.1117/1 .JRS.15.024503]
\end{abstract}

Keywords: land use/land cover change; temperature-vegetation dryness index; Ba river basin; land surface temperature; Google Earth engine.

Paper 200728 received Oct. 11, 2020; accepted for publication Mar. 12, 2021; published online Apr. 8, 2021.

\section{Introduction}

Land use and land cover (LULC) change describes modifications of the Earth's terrestrial surface caused by human activities. Analyses of LULC change can indicate causal factors and their influences on the Earth. Satellite imagery data are commonly used to detect and classify LULC change and determine spatial and temporal variations therein. ${ }^{1,2}$ Data from Landsat, Sentinel, and Moderate Resolution Imaging Spectroradiometer (MODIS) ${ }^{3,4}$ cover large areas and are freely available. ${ }^{5}$ These can be used with many algorithms to investigate LULC change. Such algorithms include, but are not limited to, maximum likelihood classification, ${ }^{6}$ minimum distance classification, ${ }^{7}$ random forest $(\mathrm{RF}),{ }^{8}$ classification and regression trees (CART), ${ }^{9}$ and support vector machines (SVM) ${ }^{10,11}$ CART is widely used in remote sensing applications and

*Address all correspondence to Thy T. M. Pham, ptmthy@vnsc.org.vn 
has advantages for both training and actual data classification. ${ }^{11}$ Organizing a large number of satellite images into a time series can be done using Google Earth Engine (GEE) ${ }^{12,13}$ with an accuracy greater than $80 \% .{ }^{13-19}$

Studies, such as Hao et al., employ GEE to identify land use changes in river basins, for example, the Yangtze basin. They show that LULC changes, such as changes in vegetative cover, affect land surface temperatures (LST) and ultimately the climate. For example, increases in vegetative cover related to reforestation activities have been associated with decreasing LST trends in forest areas. ${ }^{14,15}$ In urban areas, part of the inflation of LST has been attributed to conversion of agricultural lands and forests into built-up surfaces. In fact, LULC changes linked to urbanization have been identified as a key driver of LST increase ${ }^{16,17}$ and of changes in LST spatial distribution. ${ }^{18,19}$

Using Landsat time series imagery, Fu and Weng analyzed the impact of LULC change on LST in the Atlanta metropolitan area. ${ }^{20}$ They concluded that the mean LST values and yearly amplitude were highest for dense urban space. These authors also reported that the conversion of evergreen forest to medium-density urban land resulted in the largest changes in LST over time and the largest trend difference. Furthermore, urbanization-related LULC change brings modifications of not only LST but also surface moisture. Jiang at al ${ }^{17}$ found that the conversion of forest to commercial land altered LST and moisture more profoundly that conversion of cultivated lands to residential areas.

The rapid expansion of urban areas is mainly a product of economic growth and rising populations, especially in megacities. ${ }^{21}$ The substantial growth of built-up areas has brought a decrease in the area under water bodies, cultivated land, vegetation, and wetlands. Mohan et al. ${ }^{22}$ found major impacts of the rapid expansion of the Delhi metropolitan area from 1997 to 2008. Here, incorporation of rural areas into the urban conglomerate was associated with a 53\% drop in agricultural land, wasteland, scrubland, sandy areas, and especially water bodies. In Bangladesh and Southwest China, rapid urban expansion has been accomplished by infilling low-lying areas and clearing vegetation, which has unleashed a range of environmental impacts such as reduced habitat quality. ${ }^{23,24}$

Throughout much of the world, LULC changes associated with rapid urbanization, particularly conversion of vegetative cover to residential areas, caused abrupt increases in LST. ${ }^{25-28} \mathrm{Ha}$ and $\mathrm{Hu}^{8}$ used GEE to classify LULC in Central Asia in the period 2001 to 2017. Their results, with an accuracy greater than $90 \%$, indicate a correlation between both rainfall and dryness and land cover change, particularly in relation to farming. ${ }^{8}$ LULC change is related to climate change as well. ${ }^{29-31}$ Climate change interacts with land use planning, leading to changes in LULC, irrigation, the water environment, flood regimes, and river flow patterns. ${ }^{29,32-34}$ Some in-depth studies of LULC change combine geographical information system and analytic hierarchy process methods to assess environmental risks ${ }^{35}$ and ecoenvironmental vulnerability. ${ }^{36}$

Vietnam is considered one of the five countries most affected by climate change, with the consequences felt particularly in flood severity, drought, and sea level rise. In addition, industrial development has been a major factor driving rising LST, prolonged droughts, and desiccation in Vietnam. ${ }^{37}$ The country's economic development accelerated LULC change particularly through the conversion of forest areas for agriculture. Despite this, the current literature provides few studies on interactions between LULC change and climate change in Vietnam. This paper represents, to the best of our knowledge, the first attempt to specify the relationship between LULC change and climate change and dryness in Vietnam. Specifically, we used the temperaturevegetation dryness index (TVDI) to investigate these relationships in the Ba river basin using the cloud-based GEE platform.

The Ba basin has one of the largest river systems in central Vietnam. Moreover, this region has been severely affected by flood and drought, especially in years with El Niño phenomena. To plan for sustainable livelihoods here, it is vital to understand how interactions between LULC change and climate change could play out. Thus, our study has three main objectives:

- to use Landsat data to assess LULC changes in the Ba river basin from 2000 to 2019;

- to apply MODIS data to trace TVDI trends in the study region from 2000 to 2019;

- to specify the relationship between TVDI and LULC change in the Ba river basin during the study period. 
As the urban part of this basin is small, particularly compared to river basins elsewhere, we focused our research on changes in the land area under agriculture, forest, and water bodies and impacts of changes in these proportions on dryness, as indicated by TVDI values.

\section{Materials and Methods}

\subsection{Study Site}

The Ba river basin is one of the largest of the Vietnamese South Central Coast. It extends through three provinces: Gia Lai, Dak Lak, and Phu Yen (Fig. 1).

The basin's main river is named the Ba upstream and the Da Rang downstream. Originating at the top of Ngoc Ro mountain $(1549 \mathrm{~m})$, this river is $13,900 \mathrm{~km}^{2}$ in area and $388 \mathrm{~km}$ in length. It extends from $12^{\circ} 35^{\prime} \mathrm{N}$ to $14^{\circ} 38^{\prime} \mathrm{N}$ latitude and from $108^{\circ} 00^{\prime} \mathrm{E}$ to $109^{\circ} 55^{\prime} \mathrm{E}$ longitude (see Fig. 1). The lower part of the river forms the Tuy Hoa delta and meets the sea at the Da Rang estuary. ${ }^{38}$

To the north, east, and south, the basin is bounded by high mountains with altitudes ranging from 500 to $2000 \mathrm{~m}$. The basin consists mainly of gray soils on acid magma rock, yellow, or reddish soils on basalt, and alluvial and sandy soils, making it a favorable region for agriculture. ${ }^{38}$
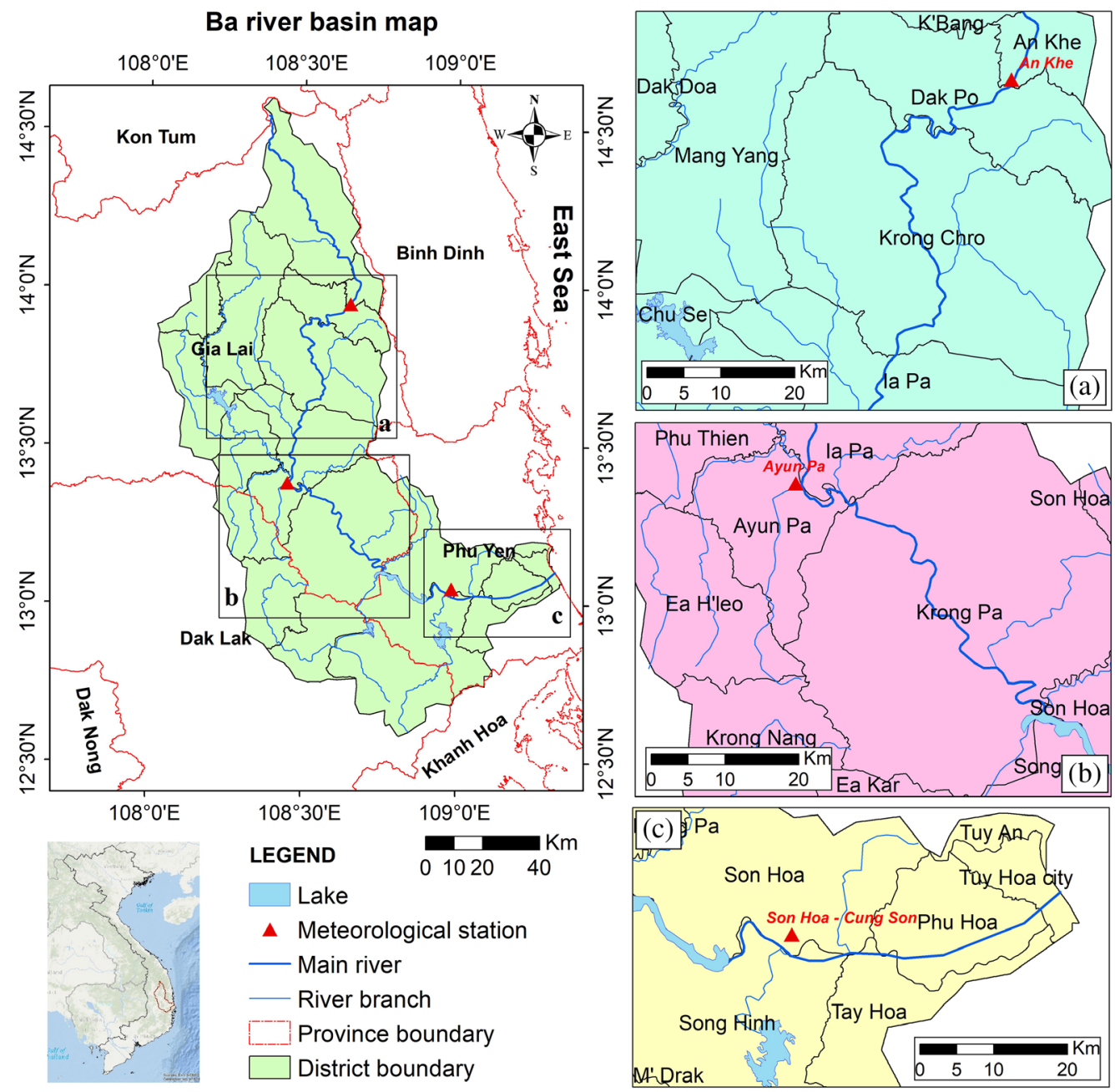

Fig. 1 Location of Ba river basin in Vietnam with three meteorological stations: (a) An Khe station, (b) Ayun Pa station, and (c) Son Hoa-Cung Son station. 
Pham et al.: Specifying the relationship between land use/land cover change and dryness...

Table 1 Landsat image details. ${ }^{39,40}$

\begin{tabular}{lcccccc}
\hline \hline No. & Year & Satellite & $\begin{array}{c}\text { Spatial } \\
\text { resolution }(\mathrm{m})\end{array}$ & ID code & Acquisition period & Scenes \\
\hline 1 & 2000 & Landsat 5 & 30 & LANDSAT/LT5_L1T_TOA & January July, 2000 & 25 \\
2 & 2005 & Landsat 5 & 30 & LANDSAT/LT5_L1T_TOA & January to May, 2005 & 20 \\
3 & 2010 & Landsat 5 & 30 & LANDSAT/LT5_L1T_TOA & January to July, 2010 & 19 \\
4 & 2017 & Landsat 8 & 30 & LANDSAT/LC8_L1T_TOA & January May, 2017 & 27 \\
5 & 2019 & Landsat 8 & 30 & LANDSAT/LC8_L1T_TOA & January to May, 2019 & 38 \\
\hline \hline
\end{tabular}

Table 2 MODIS image specifications. ${ }^{5}$

\begin{tabular}{lccc}
\hline \hline Band number & Wavelength $(\mu \mathrm{m})$ & Band name & Spatial resolution $(\mathrm{m})$ \\
\hline 1 & 0.620 to 0.670 & Red & 250 \\
2 & 0.841 to 0.876 & NIR & 250 \\
31 & 10.78 to 11.28 & TIR-1 & 1000 \\
32 & 11.77 to 12.27 & TIR-2 & 1000 \\
\hline \hline
\end{tabular}

\subsection{Data}

\subsubsection{Landsat data}

For the research, we used Landsat satellite data provided by the US Geological Survey (USGS), summarized in Table 1. The Ba river basin appears in three Landsat scenes (path/row 124/50, 124/51, and 123/51). Data were collected from 2000, 2005, 2010, 2017, and 2019, then cloud filtered and extracted for LULC classification with GEE.

\subsubsection{MODIS data}

We used MODIS data to calculate LST and normalized difference vegetation index (NDVI) values in time series and then to predict TVDI trends. The MOD11A1 version 6 product provided daily per pixel temperatures in bands 31 and 32 for the 2000 to 2019 period. The MOD09Q1 version 6 product $^{5}$ provided estimations of surface spectral reflectance in bands 1 and 2 (Table 2). These were used to calculate NDVI.

\subsubsection{Meteorological data}

Meteorological data were provided by the Vietnam Meteorological and Hydrological Administration. These included (i) mean air temperature, (ii) mean humidity, and (iii) precipitation. These data were collected at three meteorological stations in the Ba river basin (see Fig. 1 and Table 3). Two of the stations, An Khe and Ayun Pa, were part of the Central Highlands

Table 3 Climate type and coordinates of meteorological stations in the Ba river basin. ${ }^{41-43}$

\begin{tabular}{llccc}
\hline \hline No. & Station & Latitude & Longitude & Climate type \\
\hline 1 & An Khe & $13^{\circ} 57^{\prime}$ & $108^{\circ} 39^{\prime}$ & Tropical highland monsoon \\
2 & Ayun Pa & $13^{\circ} 23^{\prime}$ & $108^{\circ} 27^{\prime}$ & Dry tropical highland monsoon \\
3 & Son Hoa-Cung Son & $13^{\circ} 03^{\prime}$ & $108^{\circ} 59^{\prime}$ & Tropical monsoon \\
\hline \hline
\end{tabular}


Pham et al.: Specifying the relationship between land use/land cover change and dryness...

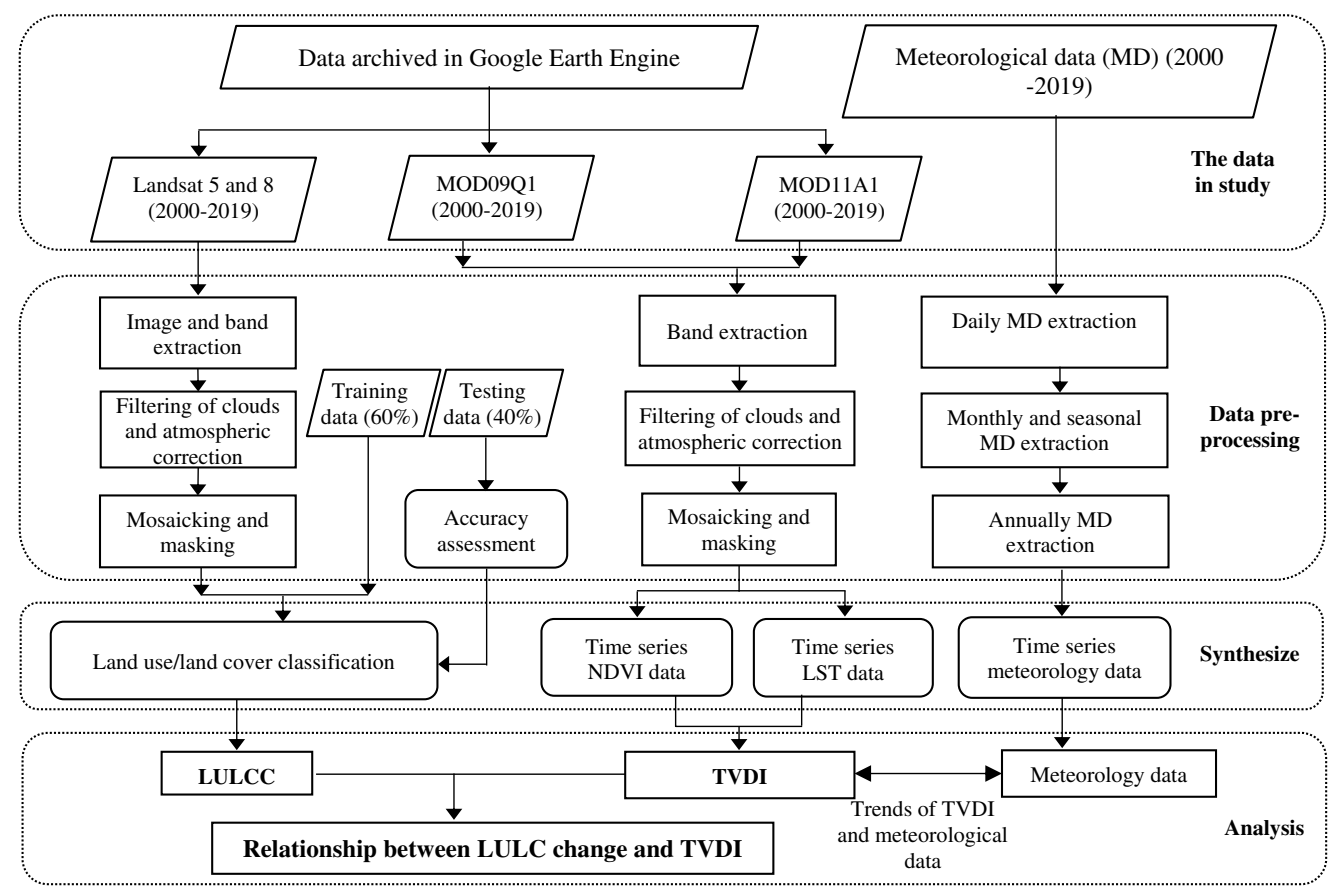

Fig. 2 Workflow of the study.

Hydrometeorological Center, ${ }^{41}$ and the third station, Son Hoa-Cung Son, was part of the South Central Coast Hydrometeorological Center. ${ }^{42}$ The meteorological data were gathered on a monthly basis from 2000 to 2019. Based on the climate zone map of the Central Highlands ${ }^{43}$ and the description of the climate at the meteorological stations, ${ }^{41,42}$ the three stations were deemed representative of the three main climate types in the Ba river basin. A highland tropical monsoon climate accounts for about half the basin area.

\subsection{Methodology and Data Processing}

Figure 2 shows the workflow of our study. The three main procedures were as follows: (i) assessing LULC change, (ii) evaluating the TVDI and meteorological data trends, and (iii) specifying the relationship between TVDI and LULC change. We used daily MODIS data from 2000 to 2019 to determine the spatial distribution and temporal variation in TVDI in the dry season.

\subsubsection{Land use/land cover change from Landsat data}

To assess LULC change over time with GEE, a total of 3413 training samples ranging from 507 to 776 for the years 2000, 2005, 2010, 2017, and 2019 were selected (Table 4). Figure 3 shows

Table 4 Summary of samples in the Ba river basin.

\begin{tabular}{lcccccc}
\hline \hline No. & Year & Agricultural lands & Forests & Water bodies & Other & Total \\
\hline 1 & 2000 & 124 & 251 & 32 & 100 & 507 \\
2 & 2005 & 250 & 249 & 80 & 174 & 753 \\
3 & 2010 & 147 & 297 & 77 & 255 & 776 \\
4 & 2017 & 160 & 328 & 90 & 172 & 750 \\
5 & 2019 & 204 & 196 & 65 & 162 & 627 \\
Total & & 885 & 1321 & 344 & 863 & 3413 \\
\hline \hline
\end{tabular}




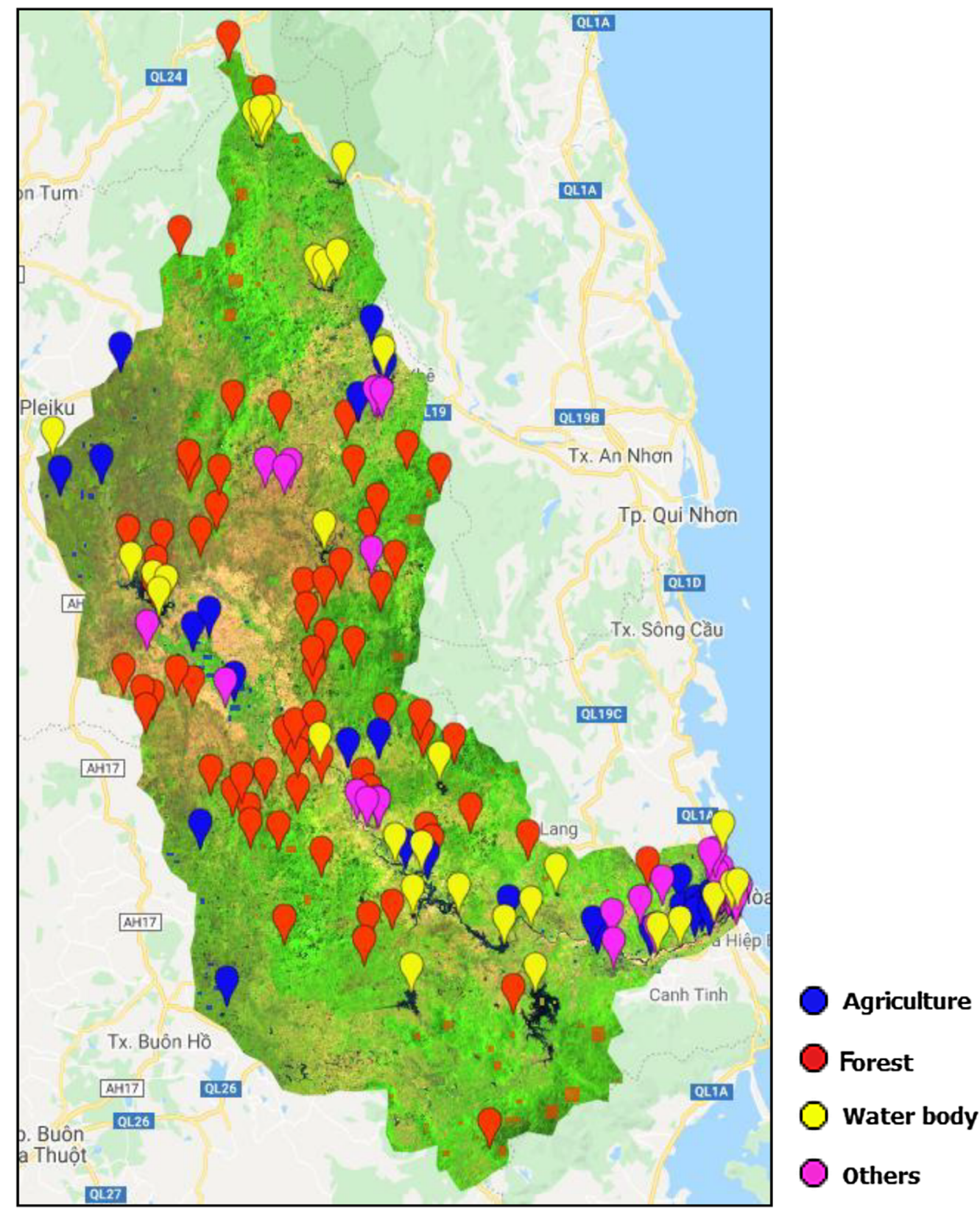

Fig. 3 Distribution of 627 training sample points used in the LULC classification of the year 2019.

the distribution of training sample points of 2019 used in the LULC classification including four main objects: agricultural lands (blue points), forests (red points), water bodies (yellow points), and other (purple points). In the Ba basin, most agricultural lands were cultivated to pepper, coffee, rubber, and cashew; forests included both old-growth and regrowth areas; water bodies consisted of rivers, streams and lakes; and other was mainly urban areas and bare lands.

GEE allows LULC categorization by the CART method. ${ }^{44}$ This is a machine learning algorithm suitable for nonlinear models. Table 4 presents the samples, which were collected by site survey and from high-resolution images in Google Earth Pro. In GEE, the research algorithm divides the data in the selected classification samples, with $60 \%$ used for image classification and $40 \%$ for verifying accuracy.

\subsubsection{Land surface temperature from MODIS data}

We evaluated LST in the Ba river basin in the 20 years from 2000 to 2019. The MODIS data (MODIS/006/MOD11A1) were preprocessed to filter clouds and for atmospheric 
correction. We then compiled 7233 daily image scenes into 233 monthly scenes using median statistics.

LST was calculated in kelvins $\left({ }^{\circ} \mathrm{K}\right)$ by multiplying the MOD11A1 product by the scale factor using the following equation: ${ }^{45}$

$$
t=a * \text { pixel, }
$$

where $t$ is the LST value $\left({ }^{\circ} \mathrm{K}\right)$, pixel is the digital number of the MODIS images, and $a$ is a technical indicator $(0.02$ for bands 31 and 32$)$. Then, we converted the results to degrees Celsius as follows: $t\left({ }^{\circ} \mathrm{C}\right)=t\left({ }^{\circ} \mathrm{K}\right)-273.15$.

\subsubsection{Temperature-vegetation dryness index values from the MODIS data}

TVDI values indicate the spatial correlation between NDVI and LST, thus allowing for assessment of the dryness of a region. In this study, we determined TVDI values based on the MODIS data.

The NDVI value was calculated from the near-infrared (NIR) and red bands as follows:

$$
\mathrm{NDVI}=\frac{\mathrm{NIR}-\mathrm{red}}{\mathrm{NIR}+\text { red }}
$$

where NIR is the reflectance of band 2 and red is the reflectance of band 1 of the MOD09Q1 product.

The TVDI value was calculated from LST and NDVI as follows: ${ }^{46,47}$

$$
\mathrm{TDVI}=\frac{\mathrm{LST}^{-\mathrm{LST}_{\text {min }}}}{(a+b * \mathrm{NDVI})-\mathrm{LST}_{\min }},
$$

where LST is the observed LST at a given pixel, LST $_{\min }$ is the minimum observed LST, NDVI is the observed NDVI value, and $a$ and $b$ are parameters defining the dry edge modeled as a linear fit to the data $\left(L S T_{\text {max }}=a+b * \mathrm{NDVI}\right)$, in which $\mathrm{LST}_{\max }$ is the maximum observed LST for a given NDVI value.

TVDI values ranged from 0 to 1 . In line with previous studies, ${ }^{48,49}$ we defined TVDI in five levels with intervals of 0.2 . Table 5 presents these intervals, which were labeled "very wet" $\left(0.0<\mathrm{TVDI}_{1} \leq 0.2\right)$, "wet" $\left(0.2<\mathrm{TVDI}_{2} \leq 0.4\right)$, "normal" $\left(0.4<\mathrm{TVDI}_{3} \leq 0.6\right)$, "dry" $\left(0.6<\mathrm{TVDI}_{4} \leq 0.8\right)$, and "very dry" $\left(0.8<\mathrm{TVDI}_{5} \leq 1.0\right)$.

\subsubsection{Relationship between LULC change and TVDI}

The 2019 data were chosen for detailed assessment and used as a basis for specifying the relationship between LULC change and TVDI. We investigated this relationship by looking at (i) the distribution of TVDI intervals over the LULC classes and (ii) the distribution of LULC classes over the TVDI intervals. The purpose of this procedure was to obtain a more specified understanding of the relationship between LULC and TVDI by associating changes in each.

Table 5 Intervals in TVDI.

\begin{tabular}{lccccc}
\hline \hline & TVDI_1 & TVDI_2 & TVDI_3 & TVDI_4 & TVDI_5 \\
\hline Value range & 0 to 0.2 & 0.2 to 0.4 & 0.4 to 0.6 & 0.6 to 0.8 & 0.8 to 1.0 \\
Label & Very wet & Wet & Normal & Dry & Very dry \\
\hline \hline
\end{tabular}




\section{Results}

\subsection{Land Use and Land Cover Change in the Ba River Basin}

To detect LULC change in the Ba river basin, we applied a supervised machine-learning classification approach in GEE using the Landsat data acquired in 2000, 2005, 2010, 2017, and 2019. Assessment of the classification results of 2017 and 2019 data using field data ${ }^{50}$ indicated an overall accuracy of $89 \%$ with a kappa coefficient of 0.77 and 0.71 , respectively.

The two classes with the largest areas were agriculture and forest (Fig. 4). In the 20 years under study, the most significant LULC changes were observed in the western, southwestern, and eastern areas of the Ba basin.

We see from Table 6 and Fig. 5 that agricultural lands increased from 290,630 ha to 686,526 ha $(+136.2 \%)$ in the 2000 to 2019 period. This translates to an annual increase of $7.17 \%$. In 2019, agricultural lands accounted for $51.5 \%$ of total basin area. The greatest rise in agricultural lands was registered in the 2005 to 2017 period, during which the agricultural area almost doubled (a $96.6 \%$ increase or rise of $5.7 \%$ per year). Growth was slower in the rest of the study period, ranging from $2.7 \%$ to $3.0 \%$ per year.

Change was most significant in Gia Lai Province [Fig. 6(a)] (Mang Yang, Kong Chro, Chu Se, Phu Thien, and Dak Po districts), Dak Lak Province [Figs. 6(a) and 6(c)] (Ea H'Leo, Krong Nang, M'Dak, and Krong Pa districts), and Phu Yen Province [Fig. 6(b)] (Song Hinh, Son Hoa, and Phu Hoa districts).

In contrast to the area under agriculture, forest area diminished by 404,410 ha or $44.6 \%$, from 2000 to 2019 (an average of $-2.35 \%$ per year). In 2000 , forests covered about $68 \%$ of the basin; yet, this expanse had diminished to $37.6 \%$ in 2019 . Forest area decreased by $17.9 \%$ from 2000 to 2005 ( $-3.58 \%$ per year). In the 2005 to 2010 period, this decline was briefly reversed, due in part to government policies, especially decision no. 611/QD-TTg, ${ }^{51}$ which mandated reforestation of 5 million hectares and decision no. 304/2005/QD-TTg, ${ }^{52}$ which allocated forest areas for
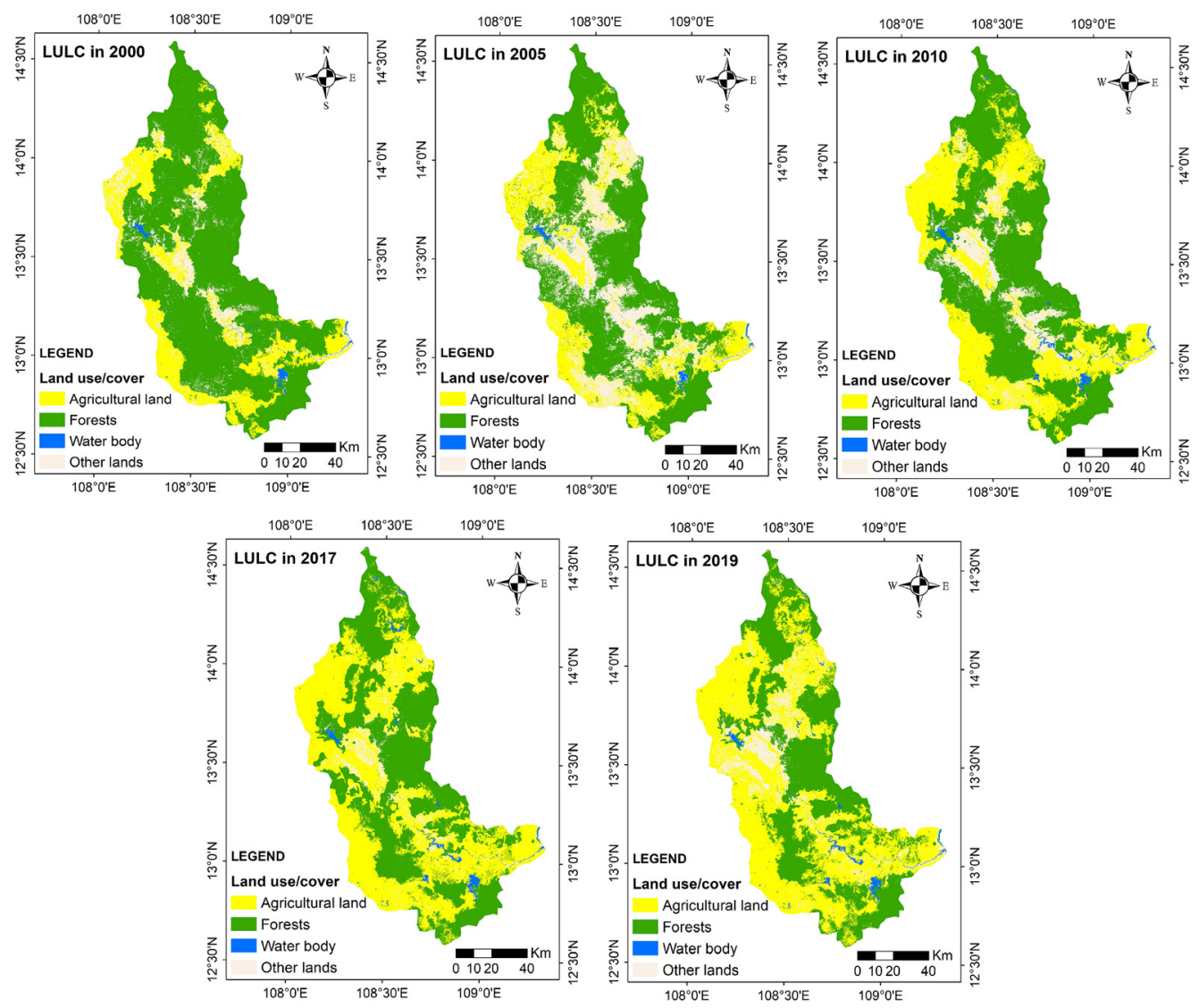

Fig. 4 Land use/land cover maps for the Ba river basin in 2000, 2005, 2010, 2017, and 2019. 
Pham et al.: Specifying the relationship between land use/land cover change and dryness...

Table 6 Land use/land cover area in the Ba river basin from 2000 to 2019.

\begin{tabular}{|c|c|c|c|c|c|c|}
\hline Land class & Area (ha) & $\%$ Area & Area (ha) & $\%$ Area & Area (ha) & $\%$ Area \\
\hline & \multicolumn{2}{|c|}{2000} & \multicolumn{2}{|c|}{2005} & \multicolumn{2}{|c|}{2010} \\
\hline Agricultural lands & 290,630 & 21.8 & 329,713 & 24.7 & 472,084 & 35.4 \\
\hline Forests & 906.138 & 68.0 & 667,614 & 50.1 & 687,526 & 51.6 \\
\hline Water bodies & 10,927 & 0.8 & 8,476 & 0.6 & 15,823 & 1.2 \\
\hline Other & 124,915 & 9.4 & 326,807 & 24.6 & 157,176 & 11.8 \\
\hline \multirow[t]{2}{*}{ Total } & $1,332,610$ & 100.0 & $1,332,610$ & 100.0 & $1,332,610$ & 100.0 \\
\hline & \multicolumn{2}{|c|}{2017} & \multicolumn{2}{|c|}{2019} & \multicolumn{2}{|c|}{2000 to 2019} \\
\hline Agricultural lands & 648,305 & 48.7 & 686,526 & 51.5 & 395,896 & +136.2 \\
\hline Forests & 602,351 & 45.2 & 501.728 & 37.6 & $-404,410$ & -44.6 \\
\hline Water bodies & 19,598 & 1.4 & 18,061 & 1.4 & 7,134 & +65.3 \\
\hline Other & 62,356 & 4.7 & 126,295 & 9.5 & 1,381 & +1.1 \\
\hline Total & $1,332,610$ & 100.0 & $1,332,610$ & 100.0 & - & - \\
\hline
\end{tabular}

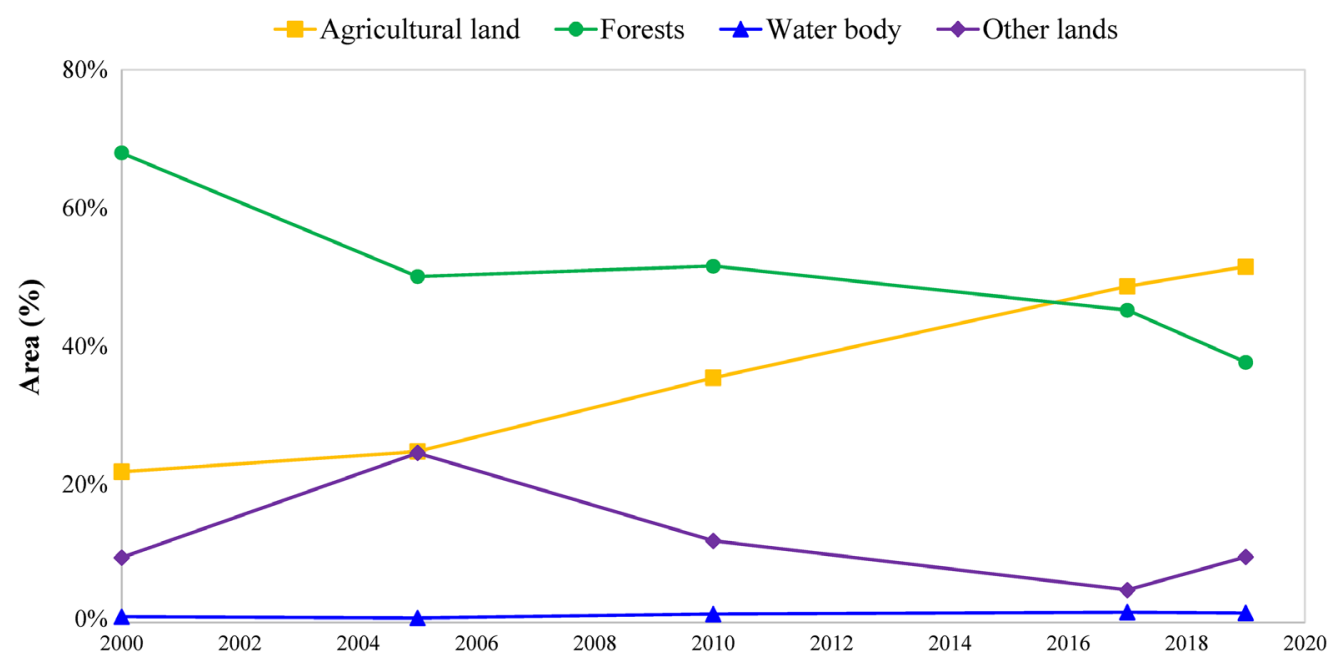

Fig. 5 Land use/land cover change rate in the Ba river basin from 2000 to 2019.

protection by indigenous peoples. Thus, forest area grew slightly, by $1.5 \%$ or $0.3 \%$ per year, during this period. However, from 2010 to 2019, forest areas continuously declined, decreasing by $13.9 \%$ in total $(-1.6 \%$ per year).

Most of the forest area in the Ba river basin was found in northern and eastern Gia Lai Province [Fig. 7(c)] (K'Bang, Mang Yang, Dak Po, Kong Chro, Ia Pa, and Krong Pa districts), in southwestern and southern Dak Lak Province [Figs. 7(a) and 7(b)] (Phu Thien, Ayun Pa, Ea H'leo, Ea Kar, and M'Drak districts), and in Phu Yen Province [Fig. 7(b)] (Song Hinh, Son Hoa, and Tuy Hoa districts). There was virtually no forest in the west and in the estuary zone of the Da Rang river.

Moreover, from 2000 to 2019, the area under water bodies increased by $65.3 \%$ due to irrigation projects and construction of hydroelectric reservoirs ${ }^{53}$ [see Figs. 7(a)-7(c)] such as at Song Ba Ha (220 MW, built 2004 to 2009), An Khe-Kanak (80 MW, built 2005 to 2011), and 


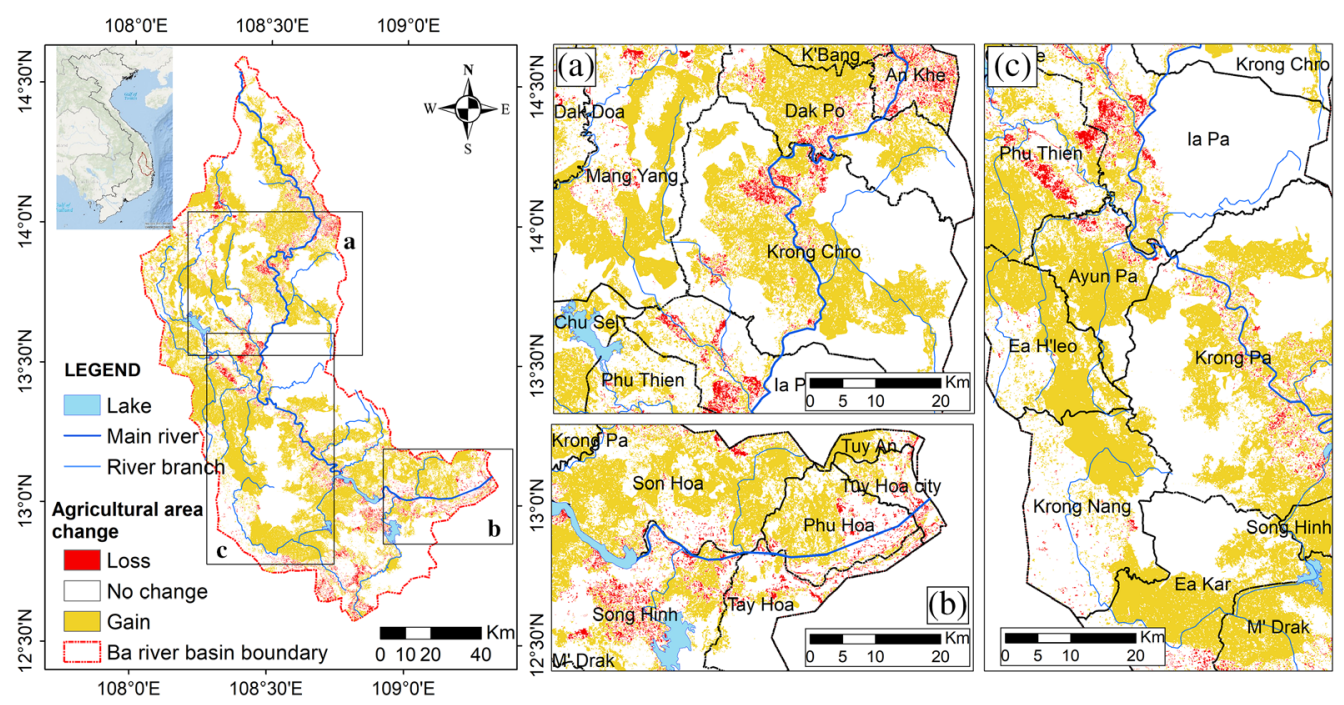

Fig. 6 Change in agricultural land area in the Ba river basin from 2000 to 2019. Insets show areas where agricultural land increases were particularly significant: (a) central Gia Lai, (b) Phu Yen, and (c) Daklak and Gia Lai.
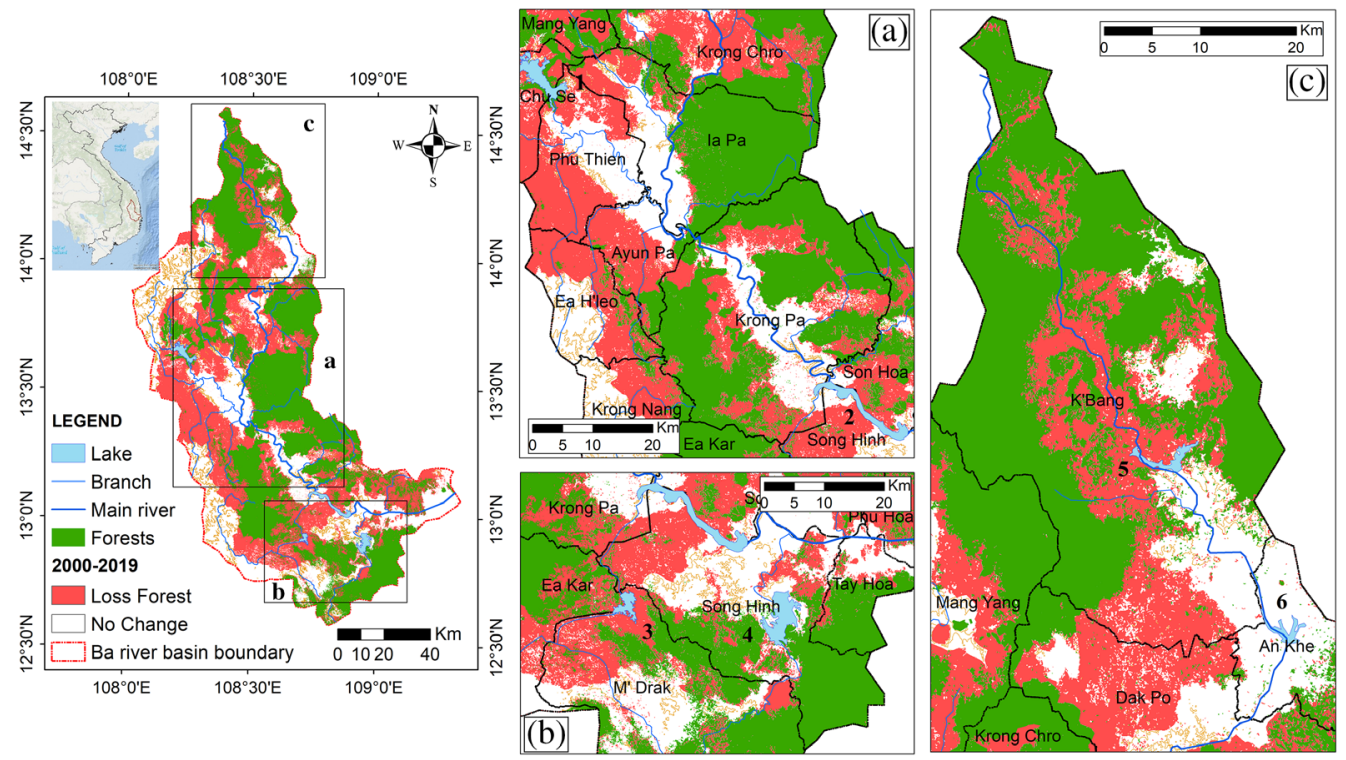

Fig. 7 Change in forest area in the Ba river basin from 2000 to 2019. Insets show areas with pronounced losses of forest: (a) Daklak and Phu Yen, (b) Phu Yen, and (c) central Gia Lai. 1. Ayun $\mathrm{Pa}$ lake, 2. Song $\mathrm{Ba} \mathrm{Ha}$ hydroelectric reservoir, 3. Krong H'Nang hydroelectric reservoir, 4. Song Hinh lake, 5. An Khe-Kanak hydroelectric reservoir, and 6. An Khe lake.

Krong H'Nang (64 MW, built 2005 to 2012). Some fluctuations were observed in the "other" land class, particularly related to the area of bare lands and reclaimed lands. Forest conversion and reclamation of other lands for agriculture expanded vigorously in the 2000 to 2005 period, from 124,915 to 326,807 ha (32.3\% per year). However, this expansion slowed remarkably in 2017 to just 62,356 ha (4.7\% per year) partly due to enactment of the settled agriculture policy for indigenous people. ${ }^{54}$ From 2017 to 2019 , some arable land was left uncultivated, as seen in the dramatic increase in the "other" land class in this period, from 62,356 to 126,295 ha, or a $102.5 \%$ increase.

Looking at overall trends, 2000 to 2019 can be summarized as a period of expanding area under agriculture $(+7.2 \%$ per year) and water bodies $(+3.4 \%$ per year $)$, with the other land class 
Pham et al.: Specifying the relationship between land use/land cover change and dryness...

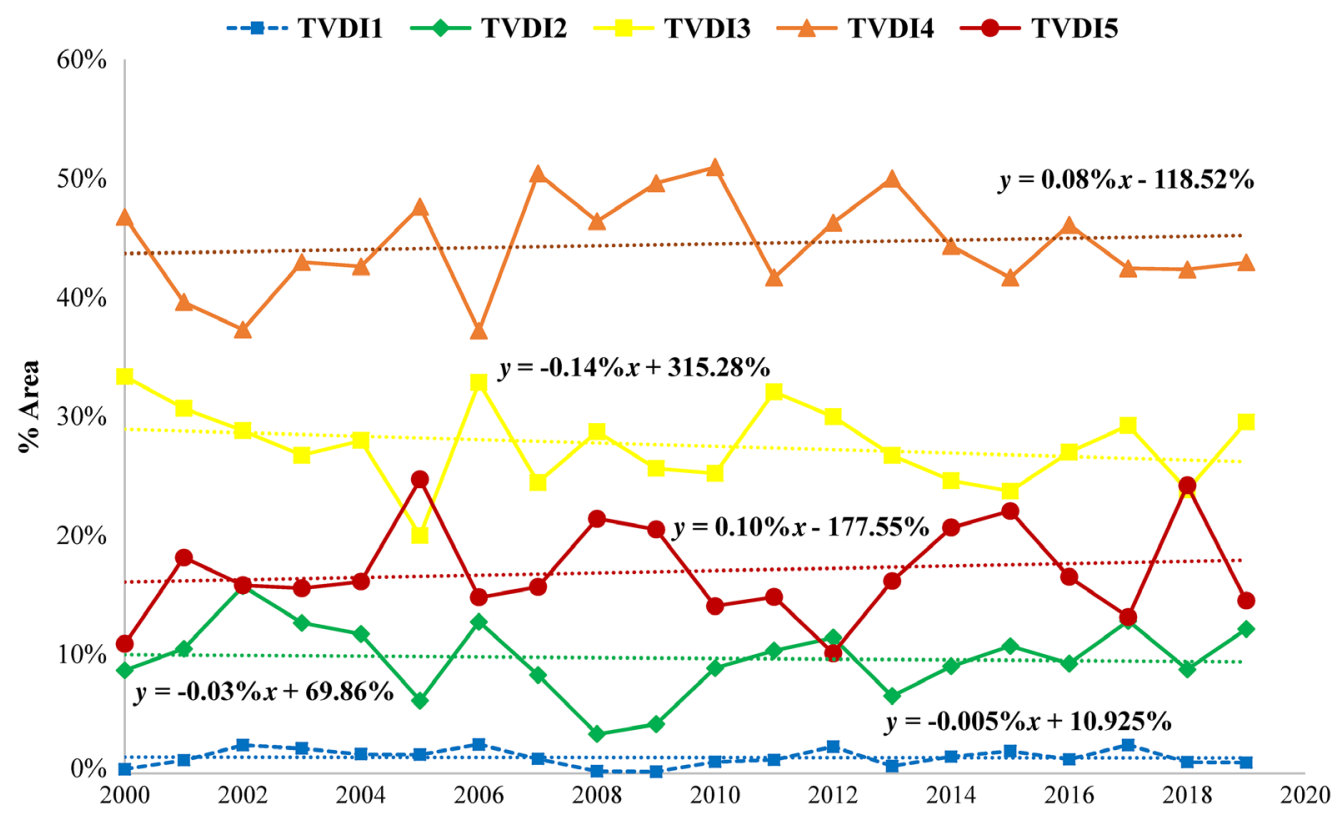

Fig. 8 Area of Ba river basin falling into each TVDI interval from 2000 to 2019. TVDI 1, TVDI 2, TVDI 3, TVDI 4 and TVDI 5 represent the proportion of very wet, wet, normal, dry, and very dry areas, respectively.

also growing but to a lesser degree $(+0.06 \%$ per year $)$ while forest area diminished $(-2.35 \%$ per year).

\subsection{Trends in Temperature-Vegetation Dryness Index from MODIS Data}

We calculated TVDI values for the Ba river basin using MODIS data acquired in the dry season (January to April) from 2000 to 2019. As noted, these TVDI values ranged from 0 to 1 and were divided into five main intervals: very wet ( 0 to 0.2 ), wet ( 0.2 to 0.4 ), normal ( 0.4 to 0.6$)$, dry $(0.6$ to 0.8 ), and very dry (0.8 to 1$)$, denoted as TVDI 1 , TVDI 2 , TVDI 3 , TVDI 4 , and TVDI 5 , respectively. We aggregated the TVDI analysis results according to the change of area in each interval per year (Fig. 8 and Table 7).

From Fig. 8 and Table 7, we see that TVDI 1 area (very wet) accounted for the smallest proportion of the basin and tended to decrease by about $0.005 \%$ per year, though this stabilized in the more recent years. TVDI 3 area (normal) represents the second-largest expanse of the basin, though land classified in this interval gradually decreased, from $33.4 \%$ in 2000 to

Table 7 Trend equations for TVDI intervals in the Ba river basin from 2000 to 2019 .

\begin{tabular}{cccccc}
\hline \hline & & & \multicolumn{2}{c}{ Area } & \\
\cline { 4 - 5 } Name & Threshold values & Dryness class & 2000 & 2019 & Trend equation \\
\hline TVDI 1 & 0 to 0.2 & Very wet & $0.3 \%$ & $0.9 \%$ & $Y=-0.005 \% * X+10.925 \%$ \\
TVDI 2 & 0.2 to 0.4 & Wet & $8.6 \%$ & $12.1 \%$ & $Y=-0.03 \% * X+69.86 \%$ \\
TVDI 3 & 0.4 to 0.6 & Normal & $33.4 \%$ & $29.5 \%$ & $Y=-0.14 \% * X+315.28 \%$ \\
TVDI 4 & 0.6 to 0.8 & Dry & $46.8 \%$ & $43,0 \%$ & $Y=+0.08 \% * X-118.52 \%$ \\
TVDI 5 & 0.8 to 1 & Very dry & $10.9 \%$ & $14.5 \%$ & $Y=+0.1 \% * X-177.55 \%$ \\
\hline \hline
\end{tabular}


$29.5 \%$ in 2019 ( $-0.14 \%$ per year). The basin areas classified as TVDI 4 (dry) and TVDI 5 (very dry) increased by $0.08 \%$ to $0.1 \%$ per year.

We see from Table 7 that over 50\% of the basin area was dry and very dry in 2019 and that these types of lands tended to increase during the research period, especially the very dry areas (TVDI 5). This points to an overall trend toward increasing dryness in this basin.

\subsection{Trends from the TVDI Time Series Compared to the Meteorological Data}

Meteorological data, specifically, monthly air temperature, humidity, and precipitation, were collected from three ground-based monitoring stations: An Khe, Ayun Pa, and Son HoaCung Son. As noted above, these stations were deemed representative of the three major climate zones found in the Ba basin (Fig. 9). We compared TVDI values for the pixels of the stations with meteorological data collected from the stations in the dry seasons from 2000 to 2019. Figures $10-12$ and Table 8 present the results.

An Khe station is located in the highland tropical monsoon climate zone (Fig. 9). The relatively low dry season air temperatures here, ${ }^{41}$ measured from $21.6^{\circ} \mathrm{C}$ to $23.8^{\circ} \mathrm{C}$, showed a gradually increasing trend, at an annual rate of $0.001^{\circ} \mathrm{C}$ (Fig. 10). As expected for a highland tropical monsoon climate, humidity and precipitation in this area were greater than those at the other two stations, which experienced more wind and rain. Dry season precipitation at An Khe station ranged from 5.9 to $87.4 \mathrm{~mm}$ and exhibited an upward trend over the study period, increasing by some $1.49 \mathrm{~mm}$ per year (Table 8 ). Humidity ranged from $80.1 \%$ to $84.4 \%$, with a decreasing tendency, diminishing at a rate of about $-0.07 \%$ per year (Fig. 10). The area around An Khe station was characterized by low vegetation density and bare lands, which absorbed heat. ${ }^{41}$

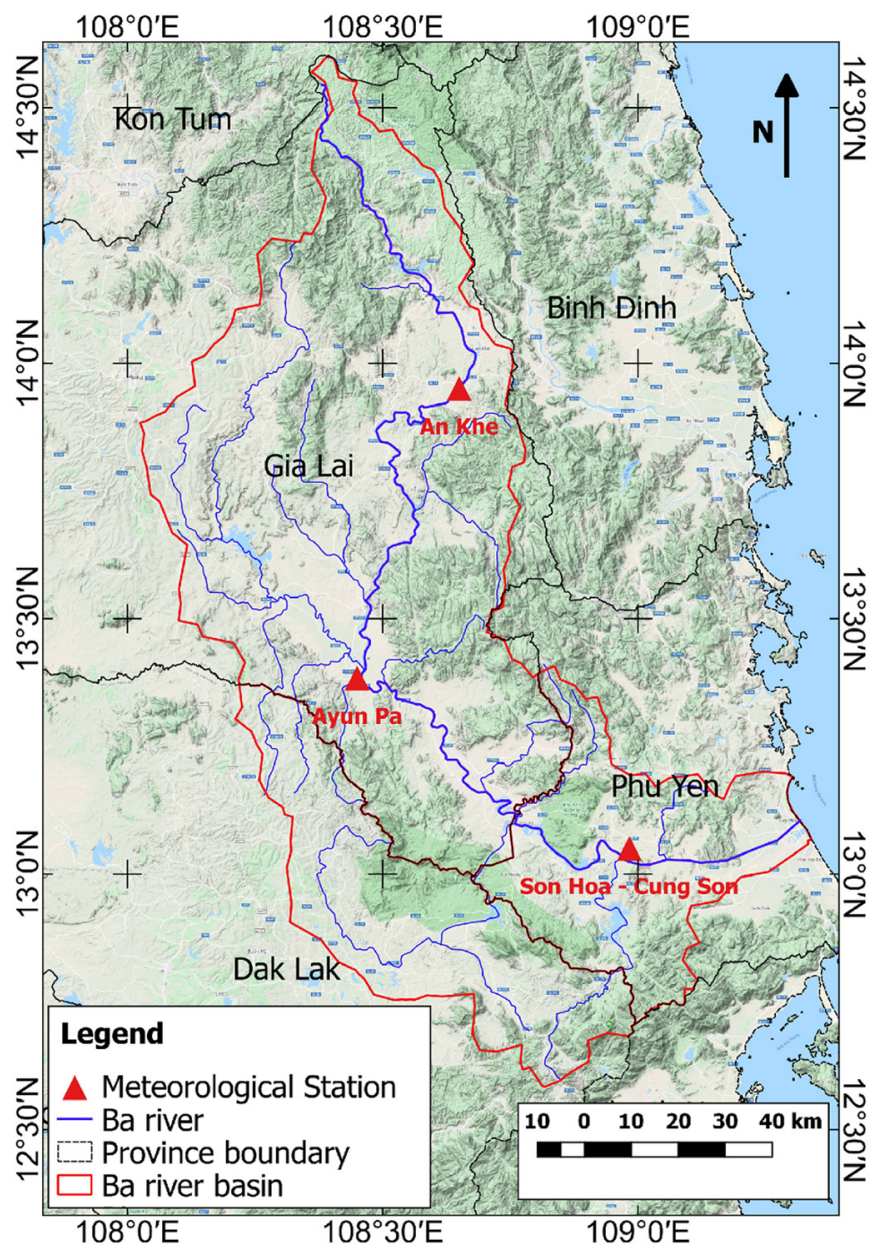

Fig. 9 Terrain model and meteorological stations in the Ba river basin. 
Pham et al.: Specifying the relationship between land use/land cover change and dryness...

TVDI and meteorological data at An Khe Station

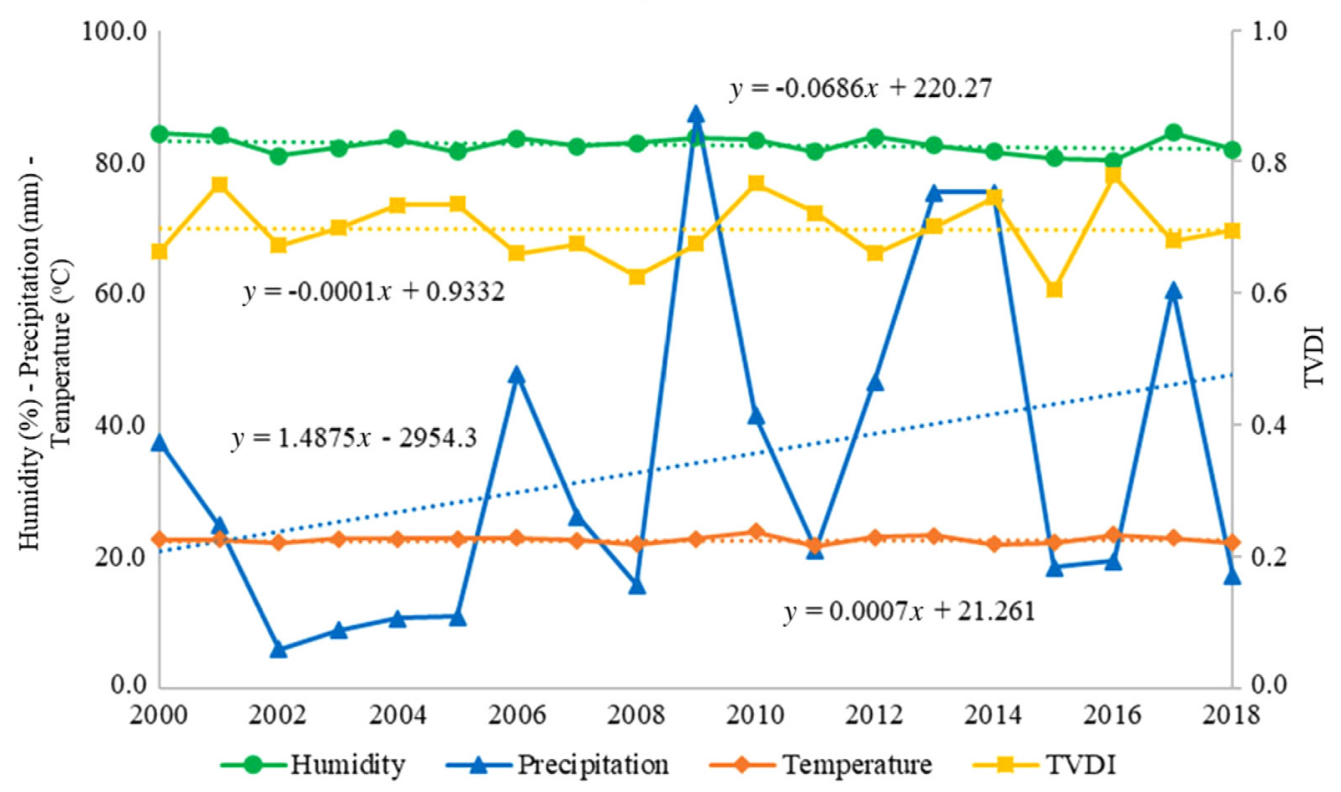

Fig. 10 TVDI and meteorological data at An Khe meteorological station from 2000 to 2019.

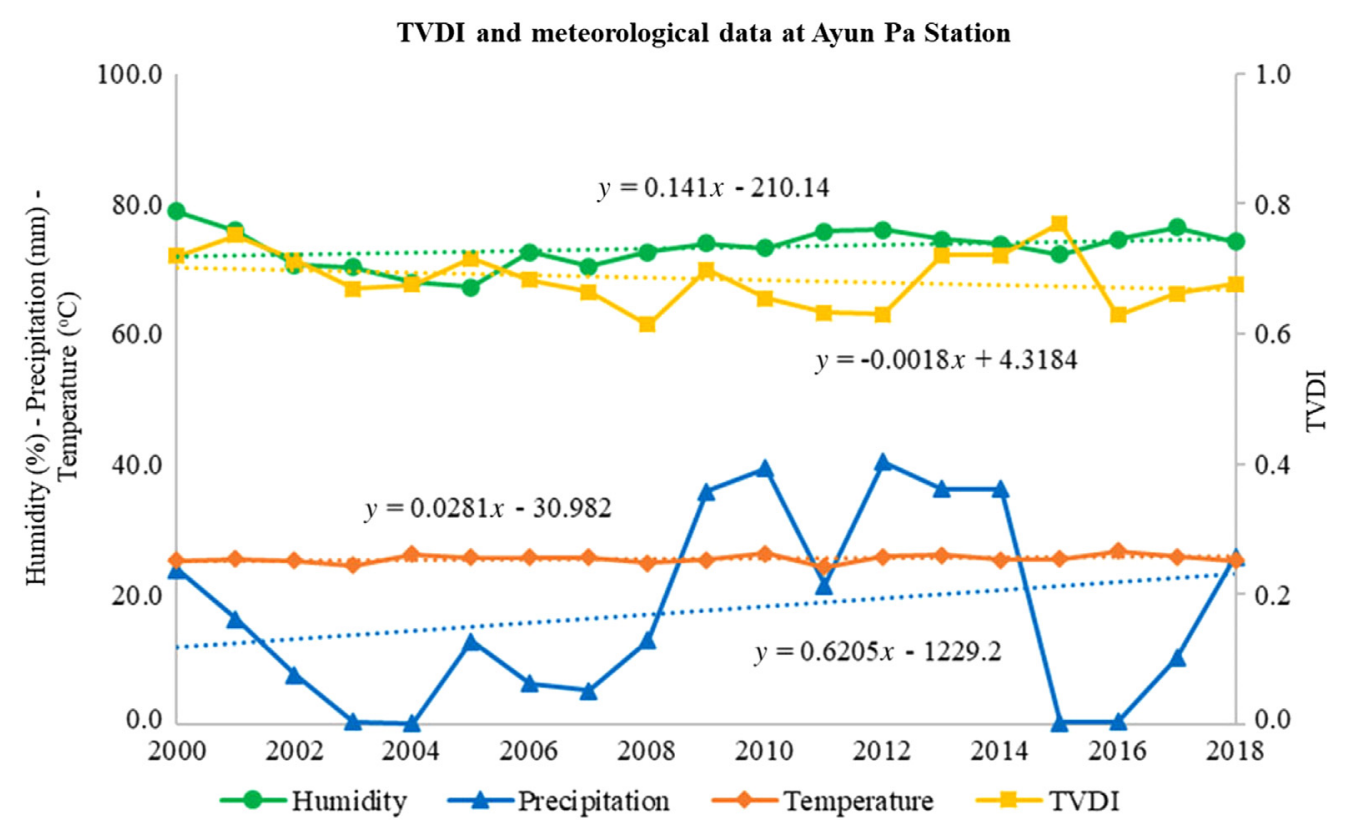

Fig. 11 TVDI and meteorological data at Ayun Pa meteorological station from 2000 to 2019.

TVDI values for this location were thus in the dry interval (0.6 to 0.8 ). In general, An Khe station and its surroundings fell into the TVDI 4 (dry) and TVDI 5 (very dry) intervals and temperatures increased while humidity decreased over the research period.

Ayun Pa station is located in the highland dry tropical monsoon climate zone (Fig. 9). As the mountainous terrain here blocks winds, air temperatures were high, ranging from $24.2^{\circ} \mathrm{C}$ to $26.7^{\circ} \mathrm{C}$, and increased by $0.028^{\circ} \mathrm{C}$ per year (Fig. 11). ${ }^{41}$ Because of the dry climate, this area had the lowest humidity values $(67.2 \%$ to $78.9 \%)$ and precipitation values $(0.2$ to $40.4 \mathrm{~mm})$ in the dry season, compared to the other two meteorological station locations. We see from Fig. 11 that precipitation and humidity here rose at a rate of $0.62 \mathrm{~mm}$ and $0.14 \%$ per year, respectively. 
Pham et al.: Specifying the relationship between land use/land cover change and dryness...

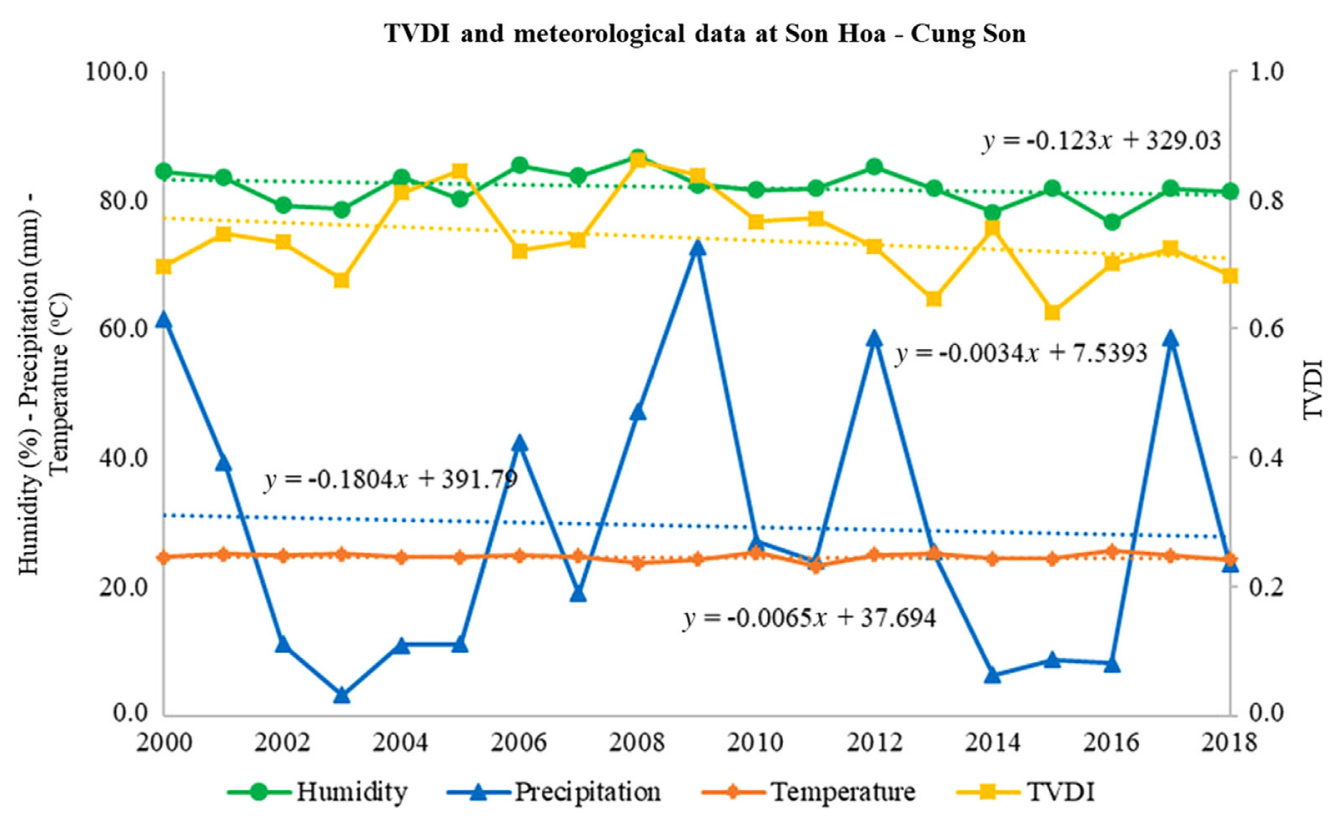

Fig. 12 TVDI and meteorological data at Son Hoa-Cung Son meteorological station from 2000 to 2019.

Table 8 TVDI values and meteorological data for three stations in dry seasons from 2000 to 2019.

\begin{tabular}{|c|c|c|c|c|c|c|c|c|c|c|}
\hline \multicolumn{2}{|c|}{ Meteorological station } & \multicolumn{3}{|c|}{ An Khe } & \multicolumn{3}{|c|}{ Ayun $\mathrm{Pa}$} & \multicolumn{3}{|c|}{ Son Hoa-Cung Son } \\
\hline No. & Value & Min & Max & Mean & Min & Max & Mean & Min & Max & Mean \\
\hline 1 & TVDI & 0.60 & 0.78 & 0.70 & 0.61 & 0.77 & 0.68 & 0.62 & 0.86 & 0.73 \\
\hline 2 & Humidity (\%) & 80.1 & 84.4 & 82.5 & 67.2 & 78.9 & 73.8 & 76.5 & 86.6 & 81.8 \\
\hline 3 & Precipitation (mm) & 5.9 & 87.4 & 24.8 & 0.2 & 40.4 & 12.9 & 3.2 & 72.8 & 24.0 \\
\hline \multirow[t]{2}{*}{4} & Temperature $\left({ }^{\circ} \mathrm{C}\right)$ & 21.6 & 23.8 & 22.7 & 24.2 & 26.7 & 25.5 & 23.2 & 25.5 & 24.7 \\
\hline & Climate type & \multicolumn{3}{|c|}{$\begin{array}{l}\text { Tropical highland } \\
\text { monsoon }\end{array}$} & \multicolumn{3}{|c|}{$\begin{array}{l}\text { Dry tropical highland } \\
\text { monsoon }\end{array}$} & \multicolumn{3}{|c|}{$\begin{array}{l}\text { Tropical monsoon } \\
\text { (hot and humid) }\end{array}$} \\
\hline
\end{tabular}

The Ayun Pa station was surrounded by grass and plants with moderate vegetation density. Thus, the mean TVDI value here was lower than that at An Khe, but it still fell into the dry interval (TVDI 4). At the Ayun Pa station, a trend of gradually decreasing TVDI values was observed, at a rate of -0.018 per year, though the TVDI 4 area in the surroundings increased.

Son Hoa-Cung Son station (Fig. 9) is in a hot and humid tropical monsoon climate zone, with correspondingly high air temperatures and high humidity. ${ }^{42}$ Air temperatures in the dry season here ranged from $23.2^{\circ} \mathrm{C}$ to $25.5^{\circ} \mathrm{C}$ and decreased at a rate of $-0.006^{\circ} \mathrm{C}$ per year over the study period (Fig. 12). Precipitation in the dry season ranged from 3.2 to $72.8 \mathrm{~mm}$ and also showed a downward trend, of $-0.18 \mathrm{~mm}$ per year. Humidity ranged from $76.5 \%$ to $86.6 \%$. Due to its location in the high temperature zone, with low vegetation density and greater urbanization, TVDI values in this area were higher than those of other two meteorological stations, falling within the dry ( 0.6 to 0.8$)$ and very dry $(0.8$ to 1.0$)$ intervals, though decreasing at a rate of 0.0034 per year.

In sum, the TDVI values and meteorological data for air temperatures, precipitation, and humidity at the three stations differed during the study period. Yet, overall, in the highlands (An Khe), the lowlands (Ayun Pa), and the plains (Son Hoa-Cung Son), TVDI values and measured air temperatures gradually increased while humidity decreased. This resulted in increased 
dryness, expressed in higher TDVI values. It must be noted, however, that our study assessed TVDI values only locally at the meteorological stations. The extent to which these results can be generalized to the respective climate zones and regions is unknown and a worthwhile topic for future research.

\section{Discussion}

\subsection{Causes of Land Use/Land Cover Change}

During the 20 years under study, agriculture was the land use class that expanded most in the Ba river basin, increasing at a rate of $7.2 \%$ per year. The reasons for this growth are twofold: socioeconomic development and the practices of indigenous people. ${ }^{54,55}$ Regarding socioeconomic development, in the Central Highlands region, in which the Ba basin is located, agricultural crops such as coffee, rubber, pepper, and cashew greatly expanded in importance over the study period. ${ }^{55,56}$ The production price of these perennial industrial crops rose by $254 \%$, $86 \%, 63 \%$, and $56 \%$, respectively, from 2000 to 2013 , according to an OECD $^{55}$ report. Moreover, the export turnover of these commodities rose, from $20.1 \%$ in 2000 to $35.1 \%$ in 2013 (Fig. 13). ${ }^{55}$

Regarding the practices of indigenous people, there has been a trend away from the custom of slash-and-burn shifting cultivation, as this form of agriculture can only be implemented in sparsely populated areas with plentiful forests and abundant natural resources. ${ }^{54,57}$ As already noted, the increase in agricultural land area in the Ba basin went hand in hand with a drop in the area under forests. Agriculture is an important income source for local populations in this region ${ }^{57}$ and when life is hard indigenous people have tended to turn to agriculture to earn more. As agricultural prices rose from 2000 to 2013, local populations gradually increased their agricultural production instead of afforestation activities.

In addition to increased agricultural area, the decline in forested areas can be attributed to population growth and infrastructure developments, particularly irrigation and hydropower projects, as well as exploitation and conversion of forests for other government-sanctioned purposes ${ }^{58,59}$ Besides, large forest areas were lost to fires, attributable largely to climate change, illegal forest exploitation, and deforestation. Loss of forests has directly affected the environment of the Ba river basin, and with it the quality of life and livelihood potential of residents here.

Furthermore, the issues of nomadism in the Central Highlands gained the attention of government during the years under study. Various programs were set up to assist the indigenous population, resulting in $82 \%$ of nomad households being sedentarized and settled. ${ }^{60}$

By the end of the study period, forest cover in the Ba river basin had been reduced to $37.6 \%$. Further continuation of this decline would bring serious consequences. In particular, disasters such as floods, landslides, and environmental degradation would become more likely.

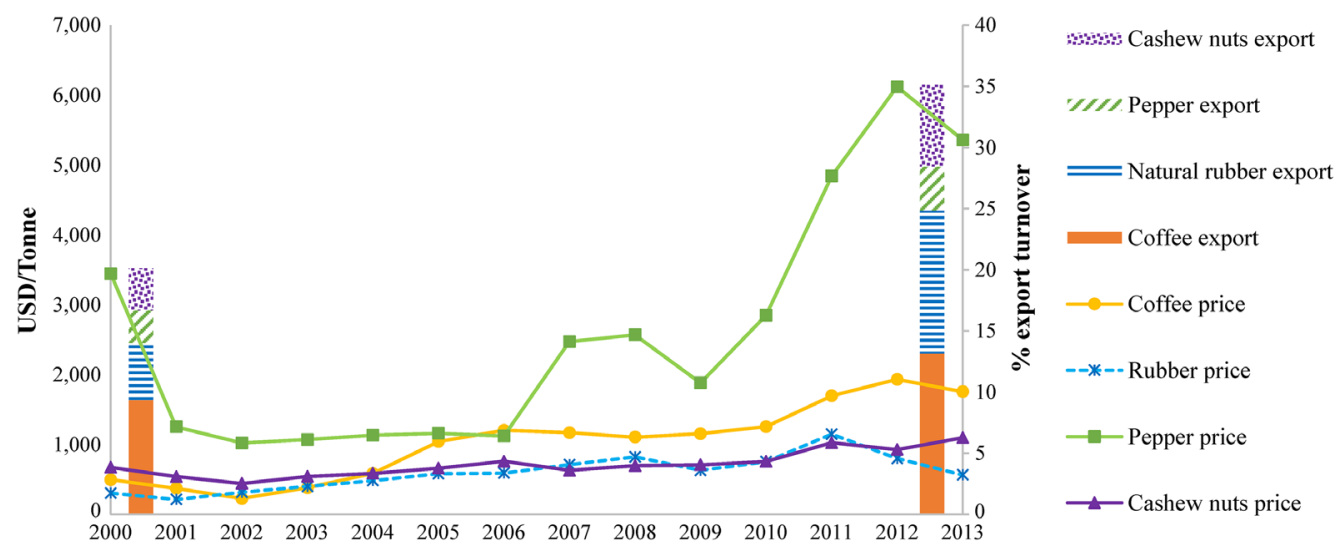

Fig. 13 Export turnover and production price of perennial industrial crops from 2000 to 2013. 
Pham et al.: Specifying the relationship between land use/land cover change and dryness...

Table 9 Distribution of TVDI intervals over the LULC classes in 2019.

\begin{tabular}{lccccc}
\hline \hline & \multicolumn{5}{c}{ TVDI intervals } \\
\cline { 2 - 5 } & 1. Very wet & 2. Wet & 3. Normal & 4. Dry & 5. Very dry \\
\cline { 2 - 6 } LULC class & 0 to 0.2 & 0.2 to 0.4 & 0.4 to 0.6 & 0.6 to 0.8 & 0.8 to 1.0 \\
\hline Agricultural land & $0.94 \%$ & $5.86 \%$ & $42.04 \%$ & $75.23 \%$ & $70.28 \%$ \\
Forests & $89.69 \%$ & $90.72 \%$ & $52.14 \%$ & $12.61 \%$ & $0.00 \%$ \\
Water bodies & $9.37 \%$ & $3.12 \%$ & $1.72 \%$ & $0.28 \%$ & $0.00 \%$ \\
Other & $0.00 \%$ & $0.30 \%$ & $4.09 \%$ & $11.88 \%$ & $29.72 \%$ \\
Total & $100.00 \%$ & $100.00 \%$ & $100.00 \%$ & $100.00 \%$ & $100.00 \%$ \\
\hline \hline
\end{tabular}

\subsection{Relationship Between Land Use and Land Cover Change and Temperature-Vegetation Dryness Index}

We investigated the relationship between LULC and TVDI by looking at (i) the distribution of TVDI intervals over the LULC classes (Table 9) and (ii) the distribution of LULC classes over the TVDI intervals (Table 10).

Regarding the distribution of TVDI intervals over the LULC classes (Table 9), we found some $90 \%$ of the TVDI 1 and TVDI 2 areas (very wet and wet) were in the forest class. These were typically mountain peaks and ridges with low surface temperatures and dense vegetation cover where high evapotranspiration resulted in a negligible impact of dryness. Moreover, 52.14\% and $12.61 \%$ of the TVDI 3 and TVDI 4 areas (normal and dry) were forest. These encompassed dipterocarps and poor forest areas with low vegetation density, as here the effects of mild and moderate dryness were felt. Some $70 \%$ of the TVDI 4 and TVDI 5 areas (dry and very dry) were found in the agricultural class. These included lands under paddy rice, pepper, corn, sugarcane, and cassava, where low to moderate vegetation density resulted in high TVDI values. Farming activities, overall, were highly represented in these driest TVDI intervals. This is because vegetative coverage on farmlands varies by season and by year, and agricultural lands are often left bare after harvest, either for recultivation later when a new crop season arrives or when farmers move on to new fields, in accordance with nomadic customs. These practices lead to unsustainable land use and cause land degradation in the long term. Finally, some $30 \%$ of lands in the TVDI 5 interval (very dry) were in the other land class (urban and bare lands).

Regarding distribution of LULC classes over the TVDI intervals (Table 10), agricultural lands represented the largest percentage of TVDI 4 (dry) areas at 56.69\%. Most forest areas

Table 10 Distribution of LULC classes over the TVDI intervals in 2019.

\begin{tabular}{llcccc}
\hline \hline & & \multicolumn{4}{c}{ LULC class (\%) } \\
\cline { 3 - 6 } \multicolumn{2}{c}{ TVDI interval (range) } & Agricultural lands & Forests & Water bodies & Other \\
\hline 1 & Very wet (0 to 0.2) & 0.03 & 4.06 & 12.11 & 0.00 \\
2 & Wet (0.2 to 0.4) & 1.86 & 39.70 & 38.94 & 0.52 \\
3 & Normal (0.4 to 0.6) & 25.18 & 43.11 & 40.59 & 13.34 \\
4 & Dry (0.6 to 0.8) & 56.69 & 13.12 & 8.36 & 48.73 \\
5 & Very dry (0.8 to 1.0) & 16.25 & 0.00 & 0.00 & 37.41 \\
Total & - & 100.0 & 100.0 & 100.0 & 100.0 \\
\hline \hline
\end{tabular}


were in either TVDI 2 (wet) or TVDI 3 (normal) with an area percentage of $39.70 \%$ and $43.11 \%$, respectively. Some forest edges were moderately affected by dryness, due to deforestation linked to shifting cultivation as well as the effects of climate change. Forests were particularly diminished and converted to agricultural lands in the northern region of the basin (Fig. 7). A large proportion of water bodies were found in the TVDI 2 (wet) and TVDI 3 (normal) intervals, respectively, $38.94 \%$ and $40.59 \%$. Finally, the largest proportions of other lands were found in the TVDI 4 (dry) interval, at $48.73 \%$, and in the TVDI 5 (very dry) interval, at $37.41 \%$. These were predominantly bare lands or urban areas, with correspondingly high temperatures and low moisture.

In general, the area of agricultural and other lands exhibited a linear relationship with TVDI. It is thus apparent that encroachment of agriculture into forest areas and the increase in urban and bare lands has worsened the severity of dryness in this basin.

\subsection{Limitations and Future Research}

This study used the GEE platform to classify LULC. A limitation of this study is its broad land classification categories, namely, agricultural lands, forests, water bodies, and other. It is recommended that future studies explore more detailed classes. For example, agricultural lands could be divided by commodity, such as coffee, pepper, cashew, and rubber. Similarly, forest could be disaggregated into natural forest, protected, and plantation forest. This would provide greater clarification of the causes of climate fluctuations and help trace the impacts of objective and subjective factors on each LULC, such as the effects of government policies and land use planning in the basin.

Moreover, it would be interesting to examine population data in more detail. Relationships might be drawn, for instance, between LULC change and practices of the ethnic Kinh and minority populations and dryness over the past 20 years. This could contribute to better understanding of the impacts of human activities, leading to more accurate forecasts of developments in the next 10 to 30 years.

\section{Conclusions}

This study analyzed a large number of Landsat and MODIS satellite images for the study area, the Ba river basin in Vietnam, using the GEE platform. Specifically, Landsat data were employed to classify LULC by CART algorithm. We extracted dry season LST, NDVI, and TVDI values from MODIS data. Our results suggest clear trends in TVDI values from 2000 to 2019. Identification of these enabled us to specify the relationship between LULC change and dryness in the $\mathrm{Ba}$ river basin.

The expanse of the Ba river basin was mapped into four classes: agricultural lands, forests, water bodies, and other (mainly urban areas and bare lands). The predominant trends in land use conversion in the Ba basin were the gradual increase in agricultural area and, to a lesser extent, an increase in water bodies. Agricultural lands grew by $136.2 \%$ over the study period, and the area under water bodies increased by $65.3 \%$. This is equivalent to an increase of $7.17 \%$ and $3.44 \%$ per year. These transformations can be attributed to economic and industrial development and increased cultivation of particular agricultural crops. At the same time, forest area decreased by $44.6 \%$, or $2.35 \%$ per year, due to conversion of forests for agriculture, illegal forest clearing, and forest fires. The decrease in forest area took place mainly in the western and southwestern regions of the basin and along the Ba river. These locations are near roads, reservoirs, and water supplies, making them particularly favorable for development of agriculture.

The TVDI index, representing the dryness of an area, was divided into five intervals: very wet, wet, normal, dry, and very dry. Areas falling into the dry and very dry intervals increased at a rate of $0.08 \%$ and $0.1 \%$ per year, respectively, according to our analysis, with these two intervals also accounting for $57 \%$ of the entire basin in 2019. Correspondingly, the proportion of the wetter TVDI intervals steadily fell. The meteorological data from the monitoring stations used to assess the TVDI results also indicated an overall gradual increase in TVDI values and air temperatures, from the highlands to the lowlands and the plains, and indicators of rainfall and humidity decreased. These findings point to increasingly severe dryness across the Ba river basin. 
Regarding the relationship between LULC and TVDI in 2019 about $90 \%$ of very wet and wet areas were found in the forests layer, where vegetation density and evapotranspiration were high. About $70 \%$ of the dry and very dry areas were found in the agriculture layer and $20 \%$ of dry and very dry areas were in the other land class (mainly urban areas and bare lands). Low to medium plant density in these areas contributed to the high TVDI values.

In summary, the expansion of agricultural lands alongside an increasing proportion of dry and very dry areas indicates a close relationship between these two factors, which caused the $\mathrm{Ba}$ river basin to heat up, affecting the livelihood prospects and quality of life of local people. Moreover, forest cover dropped over the study period, to $37.6 \%$ of basin area in 2019. Continuation of this decrease in forest cover would likely result in serious consequences, such as increasingly severe flooding, landslides, and land degradation. Appropriate land use planning and policies could help to avert such outcomes. For example, measures could seek to reduce the agricultural land area and expand the area under forests and develop more adaptive and sustainable lifestyles while building resilience in the face of climate change.

\section{Acknowledgments}

The study was carried out within the framework of the research project "Study and evaluate the impacts of climate change and socio-economic activities on the Ba/Da Rang River Basin environment by using remote sensing and GIS technology," project number VT-UD.10/18-20, which is part of the National Program on Space Science and Technology (2016-2020), Vietnam Academy of Science and Technology. We thank Professor Liou Yuei-An (National Central University, Taiwan) for commenting on the manuscript.

\section{References}

1. A. di Gregorio, Land Cover Classification System (LCCS): Classification Concepts and User Manual, Software Version 2, FAO, Rome (2005).

2. N. S. N. Lam, "Methodologies for mapping land cover/land use and its change," in Advances in Land Remote Sensing, S. Liang, Ed., pp. 341-367, Springer, Dordrecht (2008).

3. L. Carrasco et al., "Evaluating combinations of temporally aggregated Sentinel-1, Sentinel-2 and Landsat 8 for land cover mapping with Google Earth Engine," Remote Sens., 11, 288301 (2019).

4. P. S. Thenkabail, M. Schull, and H. Turral, "Ganges and Indus river basin land use/land cover (LULC) and irrigated area mapping using continuous streams of MODIS data," Remote Sens Environ. 95, 317-341 (2004).

5. MODIS, "About," NASA, https://modis.gsfc.nasa.gov/about/ (accessed 4 April 2020).

6. G. Li et al., "Land-cover classification in a moist tropical region of Brazil with Landsat TM imagery," Int. J. Remote Sens. 32(23), 8207-8230 (2011).

7. B. Su and N. Noguchi, "Discrimination of land use patterns in remote sensing image data using minimum distance algorithm and watershed algorithm," Eng. Agric. Environ. Food 6(2), 48-53 (2013).

8. Y. Ha and Y. Hu, "Land cover changes and their driving mechanisms in Central Asia from 2001 to 2017 supported by Google Earth Engine," Remote Sens. 11, 554-575 (2019).

9. H. R. Bittencourt and E. T. Clarke, "Use of classification and regression trees (CART) to classify remotely-sensed digital images," in IEEE Int. Geosci. and Remote Sens. Symp. Proc., IEEE, Toulouse (2004).

10. C. Huang, L. S. Davis, and J. R. G. Townshend, "An assessment of support vector machines for land cover classification," Int. J. Remote Sens. 23(4), 725-749 (2002).

11. Y. Shao and R. S. Lunetta, "Comparison of support vector machine, neural network, and CART algorithms for the land-cover classification using limited training data points," ISPRS J. Photogramm. Remote Sens. 70, 78-87 (2012).

12. Google Developers, "General introduction to using the Google Earth Engine platform," https://developers.google.com/earth-engine. 
13. O. Mutanga and L. Kumar, "Google Earth Engine applications," Remote Sens. 11, 591-595 (2019).

14. B. Hao et al., "Land use change and climate variation in the three gorges reservoir catchment from 2000 to 2015 based on the Google Earth Engine," Sensors 19, 2118-2142 (2019).

15. J. Zhang, L. Zhengjun, and S. Xiaoxia, "Changing landscape in the three gorges reservoir area of Yangtze River from 1977 to 2005: land use/land cover, vegetation cover changes estimated using multi-source satellite data," Int. J. Appl. Earth Obs. Geoinfo. 11, 403-412 (2009).

16. J. Jiang and G. Tian, "Analysis of the impact of land use/land cover change on land surface temperature with remote sensing," Proc. Environ. Sci. 2, 571-575 (2010).

17. Y. Jiang, P. Fu, and Q. Weng, "Assessing the impacts of urbanization-associated land use/cover change on land surface temperature and surface moisture: a case study in the midwestern United States," Remote Sens. 7(4), 4880-4898 (2015).

18. P. Singh, N. Kikon, and P. Verma, "Impact of land use change and urbanization on urban heat island in Lucknow city, Central India: a remote sensing based estimate," Sustain. Cities Soc. 32, 100-114 (2017).

19. Q. Lu et al., "Effects of urbanization and industrialization on agricultural land use in Shandong Peninsula of China," Ecol. Indic. 11(6), 1710-1714 (2011).

20. P. Fu and Q. Weng, "A time series analysis of urbanization induced land use and land cover change and its impact on land surface temperature with Landsat imagery," Remote Sens. Environ. 175(15), 205-214 (2016).

21. M. Mohan and A. Kandya, "Impact of urbanization and land-use/land-cover change on diurnal temperature range: a case study of tropical urban airshed of India using remote sensing data," Sci. Total Environ. 506, 453-465 (2015).

22. M. Mohan et al., "Dynamics of urbanization and its impact on land-use/land-cover: a case study of megacity Delhi," J. Environ. Prot. 2(9), 1274-1283 (2011).

23. A. M. Dewan and Y. Yamaguchi, "Land use and land cover change in Greater Dhaka, Bangladesh: using remote sensing to promote sustainable urbanization," Appl. Geogr. 29(3), 390-401 (2009).

24. Y. Liu et al., "Environmental effects of land-use/cover change caused by urbanization and policies in Southwest China Karst area: a case study of Guiyang," Hab. Int. 44, 339-348 (2014).

25. O. A. Fashae et al., "Land use/land cover change and land surface temperature of Ibadan and environs, Nigeria," Environ. Monit. Assess 192, 109 (2020).

26. A. M. Dewwan and R. J. Corner, "The impact of land use and land cover changes on land surface temperature in a rapidly urbanizing megacity," in IEEE Int. Geosci. Remote Sens. Symp. (IGRSS), pp. 6337-6339 (2012).

27. G. R. F Ibrahim, "Urban land use land cover changes and their effect on land surface temperature: Case study using Dohuk city in the Kurdistan region of Iraq," Climate 5, 13 (2017).

28. Q. Sun, Z. Wu, and J. Tan, "The relationship between land surface temperature and land use/ land cover in Guangzhou, China," Environ. Earth Sci. 65, 1687-1694 (2012).

29. J. Kim et al., "Impacts of changes in climate and land use/land cover under IPCC RCP scenarios on streamflow in the Hoeya River Basin, Korea," Sci. Total Environ. 452-453, 181-195 (2013).

30. B. Biazin and G. Sterk, "Drought vulnerability drives land-use and land cover changes in the Rift Valley dry lands of Ethiopia," Agric. Ecosys. Environ. 164, 100-113 (2013).

31. R. Mahmood et al., "Impacts of land use/land cover change on climate and future research priorities," Bull. Am. Meteorol. Soc. 91(1), 37-46 (2010).

32. J. A. Foley et al., "Land use, land cover, and climate change across the Mississippi basin: Impacts on selected land and water resources," Ecosyst. Land Use Change 153, 249-261 (2004).

33. H. A. Zurpani et al., "Geospatial analysis of land use change in the Savannah River basin using Google Earth Engine," Int. J. Appl. Earth Obs. Geoinfo. 69, 175-185 (2018).

34. K. E. Nyland et al., "Land cover change in the lower Yenisei river using dense stacking of Landsat imagery in Google Earth Engine," Remote Sens. 10, 1226-1246 (2018). 
Pham et al.: Specifying the relationship between land use/land cover change and dryness...

35. N. K. Anh et al., "Environmental hazard mapping using GIS and AHP: a case study of Dong Trieu District in Quang Ninh Province, Vietnam," in 8th Int. Symp. Digital Earth, IOP Publishing, Vol. 18 (2014).

36. Y. Liou, A. K. Nguyen, and M. Li, “Assessing spatiotemporal eco-environmental vulnerability by Landsat data," Ecol. Indic. 80, 52-65 (2017).

37. D. N. Anh, I. Leonardelli, and A. A. Dipierri, Assessing the Evidence: Migration, Environment and Climate Change in Vietnam, International Organization for Migration, Geneve (2016).

38. N. D. Tuan, Integrated Management of Water Resources in the Ba River Basin, Thuyloi University, Vietnam (2007).

39. Landsat Science, "Landsat 5," NASA, https://landsat.gsfc.nasa.gov/landsat-4-5/ (accessed 4 April 2020).

40. Landsat Science, "Landsat 8," NASA, https://landsat.gsfc.nasa.gov/landsat-8/missiondetails/ (accessed 4 April 2020).

41. Central Highlands Hydrometeorological Center, http://kttvtaynguyen.org.vn/ (accessed 5 September 2019).

42. South Central Coast Hydrometeorological Center, http://kttvntb.gov.vn/ (accessed 5 September 2019).

43. H. D. Cuong et al., "Research zoning of the Central Highlands climate," Vietnam J. Hydrometeorol. 647, 5-8 (2014).

44. L. Breiman et al., Classification and Regression Trees, 1st ed., Taylor \& Francis, Oxfordshire (1984).

45. Z. Wan, MODIS Land Surface Temperature Products: Users' Guide, Earth Research Institute, University of California, Santa Barbara (2013).

46. S. Niemeyer, "New drought index," Opt. Méditerr. Sér. A, 80, 267-274 (2008).

47. I. Sandholt, K. Rasmussen, and J. Anderson, "A simple interpretation of the surface temperature/vegetation index space for assessment of surface moisture status," Remote Sens. Environ. 79(2-3), 213-224 (2002).

48. C. Gao and X. Li, "Precipitation thresholds of drought disaster for maize in areas in front of Bengbu sluice, Huaihe river basin, China," Water 10, 1395-1413 (2018).

49. C. Wang et al., "Evaluating soil moisture status in China using the temperature-vegetation dryness index (TVDI)," Can. J. Remote Sens. 30(5), 671-679 (2004).

50. A. Butt et al., "Land use change mapping and analysis using remote sensing and GIS: a case study of Simly watershed, Islamabad, Pakistan," Egypt. J. Remote Sens. Space Sci. 18, 251-259 (2014).

51. Decision number 661/QĐ-TTg, Goals, Tasks, Policies and Organization of Implementation Project on Planting Five Million Hectares of New Forests from 1998 to 2010, Decision of Prime Minister of the Socialist Republic of Vietnam, Hanoi (1998).

52. Decision number 304/2005/QĐ-TTg, Piloting Forest Allocation, Contracting and Protecting Forests for Households and Communities in Villages and Ethnic Minorities in the Central Highland Provinces, Decision of Prime Minister of the Socialist Republic of Vietnam, Hanoi (2005).

53. V. T. Tam, D. T. Hung, and T. T. Le, "System analysis of water resources and proposal of sustainable water resources allocation for Ba river catchment," Vietnam J. Earth Sci. 34(1), 54-64 (2012).

54. L. T. T. Hang, P. T. Giang, and T. Q. Hoang, "Research on laws of ethnic minority and forest policies in Vietnam," Vietnam Empowerment and Accountability Programme (VEAP), Funded by the Department for International Development (DFID), London (2015).

55. OECD, OECD Food and Agricultural Reviews: Agricultural Policies in Vietnam 2015, pp. 76-128, Organisation for Economic Co-operation and Development, Paris (2015).

56. "Statistical yearbook of Vietnam," pp. 508-510, Statistical Publishing House (2018).

57. H. T. A. Chi, Land-Use Change: Consequences of Policy Reforms and Market Changes, Livelihood Pathways of Indigenous People in Vietnam's Central Highlands: Exploring Land-Use Change, pp. 50-70, Springer, Dordrecht (2018).

58. Ministry of Agriculture and Rural Development (MARD), Feasibility Report: Project on Forest Development to Improve the Livelihood in Central Highlands, MARD, Hanoi (2007). 
Pham et al.: Specifying the relationship between land use/land cover change and dryness...

59. P. T. Thuy et al., The Context of Reducing Emission from Deforestation and Forest Degradation (REDD+) in Vietnam: Drivers, Agents and Institutions, Occasional Paper 75, Center for International Forestry Research, Bogor, Indonesia (2012).

60. L. T. Anh et al., Highland Land Resources Status Quo and Challenges, Natural Science and Technology Publishing House (2016).

Thy T. M. Pham received her ME degree in geomatics from Ho Chi Minh City University of Technology (HCMUT), Vietnam National University, as well as a PhD in urbanization monitoring using remote sensing from Osaka City University, Japan. She is currently a senior researcher at the Ho Chi Minh City Space Technology Application Center (STAC)-Vietnam National Space Center (VNSC/VAST). Her main research interest is the use of satellite data for monitoring the environment, LULC and disasters.

The-Duoc Nguyen received his BE degree in environmental geology from HCMUT and his ME degree in application of remote sensing and GIS in geology from the HCMUT, Vietnam, and the University of Modena and Reggio Emilia, Italy. He is a researcher at the Laboratory Earth Resources and Environment of the HCMUT, Vietnam.

Han T. N. Tham received her BE degree in environmental management and technology from the HCMUT. She is currently a researcher at the Ho Chi Minh City Space Technology Application Center - Vietnam National Space Center.

Thi N. K. Truong received her BE degree in geology from Ho Chi Minh University of Natural Resources and Environment. She is currently a researcher at the Ho Chi Minh City Space Technology Application Center - Vietnam National Space Center.

Nguyen Lam-Dao received his ME degree in remote sensing and GIS from the Asian Institute of Technology, Thailand, and his $\mathrm{PhD}$ in radar remote sensing of vegetation from the University of Southern Queensland (USQ), Australia. He is the director of the Ho Chi Minh City Space Technology Application Center - Vietnam National Space Center. His research interests include experimental analysis and image processing toward applications.

Thong Nguyen-Huy received his PhD in applied statistics and mathematics from the USQ, Australia. He is currently a researcher at Ho Chi Minh City Space Technology Application Center - Vietnam National Space Center, and a postdoctoral research fellow at the Centre for Applied Climate Sciences of the USQ, Australia. His research interests include statistical and data-driven modeling, climate extremes and adaptations, agricultural systems, optimization, GIS, and remote sensing. 